\title{
The Most Common New Cases of Breast Cancer among the Housewives: The Some Carcinogenic Determinants
}

\author{
Nurka Pranjić ${ }^{1 *}$, Ibrahim Gledo², Ljiljana Maleš-Bilić ${ }^{3}$ \\ ${ }^{1}$ Department of Occupational Medicine, Medical Faculty, University of Tuzla, Univerzitetska 1, 75000 Tuzla, Bosnia and \\ Herzegovina; ${ }^{2}$ Department of Family Medicine, Health Care Faculty, University of Zenica, Crkvice 67, 72000 Zenica, Bosnia \\ and Herzegovina; ${ }^{3}$ Department of Occupational Medicine, School of Medicine, Banja Luka University, School of Medicine, \\ 78000 Banja Luka, Bosnia and Herzegovina
}

\begin{abstract}
Citation: Pranjić N, Gledo I, Maleš-Bilić Lj. The Most Common New Cases of Breast Cance among the Housewives: The Some Carcinogenic Determinants. OA Maced J Med Sci. 2014 Jun 15; 2(2):344-349 http://dx.doi.org/10.3889/oamjms.2014.059

Key words: breast cancer; environmental; occupational and social determinants; arival time of menopause; housewives.

"Correspondence: Prof. Nurka Pranjic, MD PHD. Department of Occupational Medicine, Medical School University of Tuzla, Univerzitetska 1, Tuzla, Bosnia and Herzegovina. Phone:+387 35320 600. E-mail: pranicnurka@hotmail.com

Received: 18-Mar-2014; Revised: 23-Apr2014; Accepted: 01-May-2014; Online first: 29-May-2014

Copyright: (c) 2014 Pranjić et al. This is an open access article distributed under the terms open access article distributed under the terms of the Creative Commons Attribution License, which permits unrestricted use, distribution, and reproduction in any medum, provided original author and source are credited.

Competing Interests: The authors have declared that no competing interests exist.
\end{abstract}

\begin{abstract}
BACKGROUND: Numerous studies have observed risk factors for breast cancer. We aimed to investigate and assess the relationship between individual, social, occupational and environmental determinants of breast cancer using a questionnaire among 100 newly diagnosed female breast cancer patients and 100 control female subjects without cancer.

METHODS: A case-control study using a family ambulatory based survey was conducted among 200 female patients from all municipalities of Zenica - Doboj Canton. New cases of breast cancer among subjects of experimental group $(n=100)$ were diagnosed between January 1,2003 and December 31, 2007 using the institutional clinical procedure for breast cancer diagnosis. Data were obtained using a self - rated questionnaire specially designed for this research. The questionnaire contains a group of questions about individual and demographic data, occupational and environment characteristics, reproductive hystory, body mass index, life style and quality life factors.

RESULTS: Fifty two percent of our examinees with breast cancer are housewives. There were no significant differences between the two groups and their subgroups except for prevalence of routine physical activity $(P=0.016)$, unemployment $(P=0.004)$, history arrival menopause $(P=0.012)$, and type of occupation/ workplace $(P=0.015)$ among subjects with breast cancer in relation to control subjects. We found significantly higher prevalence for failure to routine physical activity $(P=0.006)$, obesity $(P=0.009)$, unemployment $(P=0.001)$, unsecure existence $(P=0.015)$, and low level of education $(P=0.001)$ in housewives in relationship to others occupation.

CONCLUSION: The most common new cases of breast cancer were among housewife. Inverse significantly link between breast cancer and poverty, arrival time of menopause and distant-cousindegree family history were found. For most women, physical activity may reduce the risk of invasive
\end{abstract} breast cancer.

\section{Introduction}

What do we currently know about the social and environmental causes of breast cancer? Although it is considered that the development of breast cancer result of the interaction of genetic factors we do not yet know aetiology of breast cancer [1-3]. From 85 to $90 \%$ of cases remains unknown, although it is believed that environmental factors play a leading role and predicted breast carcinoma in $75 \%$ cases of cancer [4-5].

The incidence of breast cancer is higher among women with higher social economic status and higher educational level. Women living in urban areas have a higher risk for breast cancer development than women in rural areas [6-7]. A considerable socioeconomic difference prevailed in the burden of breast cancer among Danish women in 1970-1995. Academics had the highest risk and women working in agriculture had the lowest risk [8].

Recent research has shown that obesity and physical inactivity are poor combination of increased risk of developing breast cancer [9-12]. Breast cancer is a classical hormone- dependent tumour, and estrogens are well known to play a major role in the development and progression of the disease. Referring to thought that insufficient consumption of 
food calories cause weight gain resulted of the effects of estrogens and growth factors is associated with increased incidence of breast carcinoma [13]. Obesity itself is a risk factor for breast cancer because it leads to increased concentrations of endogenous estrogens [14-16]. About $8 \%$ cases of breast cancer in the United Kingdom was linked with overweight (BMI from 26-30) and obesity (BMl>30) [9, 17]. A growing body of evidence indicates a strong association between diabetes and cancer [18].

The incidence of breast cancer has increased trend with increasing years of age, which doubling every ten years until menopause, and then grow very slowly. So, it is extremely rare in women younger than 20 years and among women with 80 years [19]. Only $0.8 \%$ of breast cancers develop in women younger than 30 years, and approximately $6.5 \%$ occurs between 30 and 40 years of life [4].

Numerous studies indicate a growing risk of breast cancer in women occupationally exposed to polycyclic aromatic hydrocarbons (PAHs), some solvents, pesticides, some metals, chemical and textile industry [20]. The growing risk of breast cancer was observed in women employed in the pharmaceutical industry, production of cosmetics, hairdressers, nurses, laboratory technicians, dental hygienists and automobile production. There is listed exposure to carcinogens or chemicals in all occupations [21].

The aim of this study is to assess the relationship between individual, social, occupational and environmental determinants of breast cancer in industrial Zenica - Doboj Canton in Bosnia and Herzegovina.

\section{Material and Methods}

\section{Survey methods}

A case control study done by survey was conducted with the purpose of researching the connections between exposure to various social, occupational and environmental determinants and the development of newly discovered breast cancer in women treated at family health centres in the area of Zenica- Doboj Canton. This research encompassed 200 women, including 100 diagnosed with breast cancer according to clinical features (experimental group) and 100 examinees who have not been diagnosed with breast cancer or any other malignant diseases, but who underwent preventive ultrasonography examinations with family medicine physician with the aim of health promotion and primary prevention, early detection and screening of breast cancer (selected physicians did ultrasonic breast examination along with clinical examination). Examinees from the experimental group were diagnosed with breast cancer in the period between January 1, 2003 and December 31, 2007. The diagnosis was confirmed based on the clinical examination, ultrasonographic breast examination, mammography and histopathologically confirmed biopsy diagnosis or during the operative treatment "ex tempore".

\section{Sample of female respondents}

Selection of the examinees required the consent of an examinee to participate in the study, as well as on the breast cancer patient's general condition, which dependent on the severity of the clinical features. Patients from the experimental group in the terminal phase of the disease, along with benign breast tumours and clinically unsecured breast cancer diagnosis, were not included in the sampling. All examinees were classified according to age and occupation/ working place, e.g. housewives $(n=94$, $47 \%)$, retired persons ( $n=41,21 \%$, mostly have role as housewives), teachers ( $n=7)$, health care workers $(n=20)$, administration workers $(n=12)$, workers in manufacturing $(n=16)$ and those employed in the service industry $(n=10)$. Housewives constituted the largest group, making up from $52 \%$ of women with breast cancer (and $24 \%$ retired wives). Information on body mass index, employment/ secure existence, wealth status and living place (countryside, city or an apartment close to industrial facilities) was also included in this research. We did not find any statistically significant difference between the examinees of the experimental and control groups ( $p$ $>0.05)$, nor the subgroups of the selected variables $(p$ $>0.005)$, except for the wealth status variable ( $p<$ 0.001 ; data not presented). A significantly higher number of the examinees of the experimental group are in the category of poverty compared to the control subjects (31:17 vs. $31 \%: 17 \%)$.

\section{Questionnaire items and measures}

The research was conducted according to the survey method, and the instrument of the research was a questionnaire specially designed for this research. The 'questionnaire about breast factor risks' came into existence based on the experience of evidence based medicine. Before commencing the study, examinees were provided with necessary information about the aims and the purpose of the research. Filling in the questionnaire met the requirements for ethical anonymity. The questionnaire contains a group questions about individual, social and demographic data (such as age, education, main lifetime occupation, employment, place of living, wealth status, satisfaction of financial situation, physical activity: is she active, and how much); a group questions related breast cancer history within a familiar history of breast cancer (such as arrival time of menarche and menopause, childbirth history, breast fed history, contraception use history, hormone therapy history, data of hormone replacement therapy, 
previous breast diseases: cystic formation, atypical hyperplasia, carcinoma in situ, previous forms of carcinoma); a group questions related to exposure to occupational and environmental risks, how much and for how long (stress, chlorinated compounds, mercury, PAHs and other vapours); questions of smoking habits and alcohol consumption (how much and for how long) [3, 6-8, 22].

\section{Statistical Analysis}

For the statistical analysis, standard methods of descriptive statistics were used (central tendency measures and dispersion measures). In favour of testing differences of statistical significance, among the samples parametric and non- parametric significance tests were used ( $\mathrm{X} 2$ test, Man-Whitney $\mathrm{z}$ test). For linear correlation analysis a Tukey test was used (ANOVA). However, for multivariate analysis we used ANOVA (logistic regression analysis). Breast cancer was the dependent variable. Multivariate regression analyses for witch, the selected occupation are a housewife was a potential carcinogen predictor, but modified variables (potential retrograde factors) were age, BMI, employment, wealth status, and living place, occupational and environmental risk factors. All variables which were used in logistic regression analysis were divided into two different groups. The odds ratio (OR; statistically significant $O R>1.0)$ and $95 \%$ confidence interval were calculated. Statistical hypotheses were tested at a significance level of $p<$ 0.05. Data analysis was performed using SPSS version 19.0.

\section{Results}

The highest number of examinees was in the age group above 45 years in both groups, the experimental one with $83 \%$ of breast cancer and $79 \%$ in the control group without cancer. Only 15 (15\%) women employed Patients who are suffering from breast cancer usually live in the countryside. Body mass index reveals (mean value: $29.09 \pm 4.024$ ) unhealthy approach to personal health examines with breast cancer and control subjects $\left(71 \%\right.$ vs. $63 \% ; x^{2}=$ $47.03, P=0.125)$. When we analysed physical activity as a factor of healthy way of living, we can say that $70 \%$ of patients in both groups does not practice it. The genesis of menopause come earlier with patients diagnosed with breast cancer than with control subjects $\left(x^{2}=10.87, P=0.012\right)$. The examinees are also different by the history of the menopause genesis. Menopause significantly posed earlier with examinees diagnosed breast cancer in relation to control subjects.

According to our samples, housewives, 52\% of them, most often are affected by breast cancer, retired women are second with $24 \%$ and among employed women, those from manufacturing service are third. There is significant difference according to occupation as category between the groups $\left(\mathrm{X}^{2}=\right.$ 15.852, $\mathrm{P}=0.015$; Table 1).

Table 1: The distribution of the examinees according to exposure to environmental factors compared among the groups.

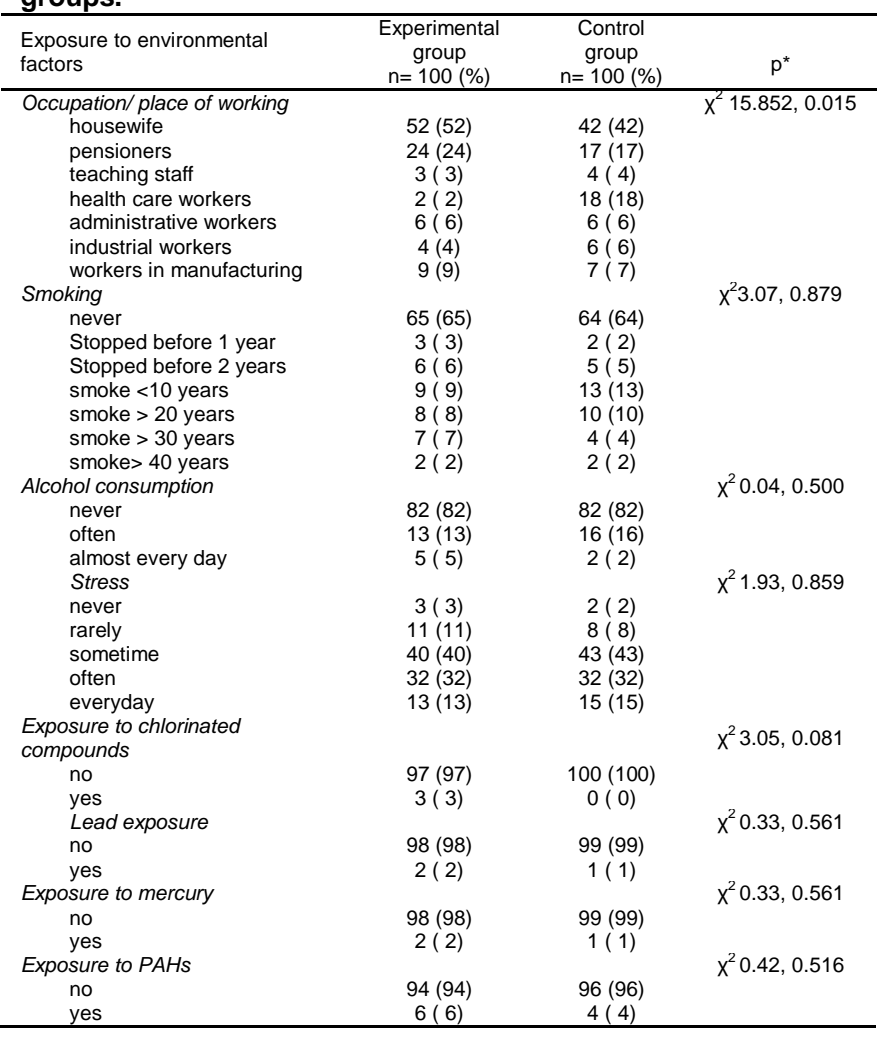

There were significantly higher prevalence for failure to routine physical activity $(P=0.006)$, obesity $(P=0.009)$, unemployment $(P=0.001)$, unsecure existence $(P=0.015)$, and low level of education $(P=$ 0.001 ) in housewives in relationship to others occupation (shown in Table 2).

Regression analysis at which breast cancer was the dependent variable, and life style and way of living factors were independent variables, it come to our knowledge that there were some differences for breast cancer. Statistically significant relative risk for breast cancer genesis is increasing age over 45 (OR $=1.2586,95 \% \mathrm{Cl}, 0.6919-2289)$. Statistically significant relative risk for breast cancer origin is bad wealth status $(O R=1.1449)$ and dissatisfaction with mentioned $(\mathrm{OR}=1.1664$, Table 3$)$. latrogenic radiation exposure to $\mathrm{X}$-rays up to 3 years is a significant relative carcinogenic risk $(O R=1.290)$. But it should be noted that exposure to $\mathrm{CT}$ diagnosis of $2 \mathrm{X}$ or more doubles the risk $(\mathrm{OR}=2.022)$. The length to the cigarette smoke exposition represents important risk factor with examinees who smoke $(\mathrm{OR}=1.531)$, the exposure to smoke from family members $(\mathrm{OR}=$ 1.260), the exposure to smoke at a workplace with examinees who are non- smokers $(\mathrm{OR}=1.220)$. When we analyze the family predisposition to breast cancer we see there is significant relative risk if a 
Table 2. Differences between housewives and other professions for some individual and socio-economic characteristics.

\begin{tabular}{|c|c|c|c|}
\hline & $\begin{array}{c}\text { Housewives } \\
n=94\end{array}$ & $\begin{array}{l}\text { All other } \\
\text { occupation } \\
\text { s } n=106\end{array}$ & $P^{*}$ \\
\hline Age subgroups (years) & & & $x^{2} 0.464,0.793$ \\
\hline $26-35$ & $2(2)$ & $3(3)$ & \\
\hline $36-45$ & $14(15)$ & $19(18)$ & \\
\hline$>45$ & $78(83)$ & $84(79)$ & \\
\hline Routine physical activity & & & $x^{2} 16.134,0.006$ \\
\hline never & $37(39)$ & $20(19)$ & \\
\hline rarely & $32(34)$ & $50(49)$ & \\
\hline $1 \mathrm{X}$ a week & $3(3)$ & $14(13)$ & \\
\hline $2 \mathrm{X}$ a week & $4(4)$ & $4(3)$ & \\
\hline $3 \mathrm{X}$ a week & $2(2)$ & $2(1)$ & \\
\hline everyday & $16(17)$ & $16(15)$ & \\
\hline Body mass index (BMI) & & & $x^{2} 60.474,0.009$ \\
\hline malnutrition & $2(2)$ & $2(2)$ & \\
\hline ideal weight & $12(13)$ & $40(38)$ & \\
\hline overweight & $44(47)$ & $48(45)$ & \\
\hline obesity & $36(38)$ & $16(15)$ & \\
\hline $\begin{array}{l}\text { Employability/secure } \\
\text { existence }\end{array}$ & & & $x 2146.40,0.001$ \\
\hline unemployment & $71(75)$ & $10(9)$ & \\
\hline employees & $0(0)$ & $52(49)$ & \\
\hline pensioners & $16(17)$ & $44(42)$ & \\
\hline other income & $7(8)$ & $0(0)$ & \\
\hline Wealth status & & & $\times 215.735,0.015$ \\
\hline the best & $1(1)$ & $0(0)$ & \\
\hline $\begin{array}{l}\text { much better than } \\
\text { others }\end{array}$ & $0(0)$ & $2(2)$ & \\
\hline better than others & $6(6)$ & $17(16)$ & \\
\hline average & $58(62)$ & $68(65)$ & \\
\hline below average & $17(18)$ & $12(11)$ & \\
\hline much worse & $7(7)$ & $1(1)$ & \\
\hline poverty, deprivation & $5(5)$ & $6(5)$ & \\
\hline Place of residence & & & $x^{2} 2.371,0.306$ \\
\hline city & $36(36)$ & $47(47)$ & \\
\hline countryside & $58(58)$ & $46(46)$ & \\
\hline $\begin{array}{l}\text { close to industrial } \\
\text { facility }\end{array}$ & $6(6)$ & $7(7)$ & \\
\hline Education & & & $x 296.897,0.001$ \\
\hline $\begin{array}{l}\text { Incomplete } \\
\text { elementary school }\end{array}$ & $47(50)$ & $11(10)$ & \\
\hline Elementary school & $36(39)$ & $15(14)$ & \\
\hline Vocational school & $7(7)$ & $41(39)$ & \\
\hline Secondary school & $4(4)$ & $20(19)$ & \\
\hline College & $0(0)$ & $11(10)$ & \\
\hline University & $0(0)$ & $8(8)$ & \\
\hline
\end{tabular}

sister was affected by the breast cancer $(\mathrm{OR}=$ 1.5247). If grandmother was affected by breast cancer the risks grows lower $(\mathrm{OR}=2.211)$, and if a distant relative had breast cancer the relative risk doubles comparing to the case with grandmother $(\mathrm{OR}=$ 4.422). Examinees who did not gave birth to a child have the growing risk of breast cancer $(\mathrm{OR}=1.394)$, while the usage of hormone replacement therapy (OR $=1.826)$ and time of the menopause $(\mathrm{OR}=1.394)$ as well represent important breast cancer risk factors. Statistically significant is the time of menarche $(O R=$ 2.651) and previously cystic breast changed $(\mathrm{OR}=$ 1.165). The alcohol is also significant breast cancer risk factor $(\mathrm{OR}=1.728$; Table 3$)$.

Not practicing the physical activity is significant predictor of the breast cancer genesis and it has been discovered by Multiple logistic regression analyses $(\exp (B)=0.067,95 \% \mathrm{Cl} 0.009-0.504 ; \mathrm{P}=$ 0.005 , data not showed).

According to the regression analyses (Model $1,2)$ at witch breast cancer was dependent variable; independent variables were age, wealth status, satisfaction with financial situation, home, smoking, alcohol consumption, and duration of the working experience; and selected dichotomised variable which represents type of occupations as potential aggravating factor of breast cancer (1. housewives, as selected variable in model 1; and 2 . other occupations, as selected factor in Model 2). There were not significant predictors in Model 1, and only one predictor which related to working experience in Model 2 (Table 4).

Table 3: The association between potential risk-factors (independent variables) and breast cancer (dependent variable) among respondents with breast cancer $(n=100)$.

\begin{tabular}{lcc}
\hline & \multicolumn{2}{c}{ Relative risk OR and 95\% } \\
Independent variables, potential relative risk & Confidence Interval $(95 \% \mathrm{Cl})^{*}$ \\
\cline { 2 - 3 } factors & OR & $95 \% \mathrm{Cl}$ \\
\hline Age $>45$ godina & 1.2586 & $0.691-2.289$ \\
Occupation & 0.9004 & $0.781-1.037$ \\
Financial state of family & 1.0362 & $0.766-1.401$ \\
Place of residence & 1.0993 & $0.642-1.882$ \\
Educational level & 0.9508 & $0.736-1.227$ \\
Pervious place of residence (before war) & 1.0827 & $0.687-1.704$ \\
Worse financial state of family & 1.1449 & $0.770-1.701$ \\
Dissatisfaction with financial state of family & 1.1664 & $0.844-1.610$ \\
Breast cancer had sister & 1.5247 & $0.505-4.599$ \\
Breast cancer had aunt & 0.6280 & $0.144-2.722$ \\
Breast cancer had grandmother & 2.2111 & $0.196-2.487$ \\
Breast cancer had further relative & 4.4222 & $0.483-4.043$ \\
Length of exposure time (years) & 1.1883 & $0.795-1.775$ \\
Prior cystic breast changed & 1.1659 & $0.354-3.830$ \\
Exposure to CT ( $>2 X$ per years) & 2.0227 & $1.254-3.261$ \\
Exposure to nuclear medicine radiation & 1.0337 & $0.690-1.548$ \\
Never birth child & 1.3947 & $0.808-2.407$ \\
Birth child or children & 0.9387 & $0.664-1.326$ \\
Had intentional abortions & 0.9124 & $0.712-1.169$ \\
Breast- feeding & 0.9394 & $0.708-1.241$ \\
Used contraception & 0.7779 & $0.549-1.101$ \\
Used hormonal therapy & 0.6015 & $0.049-7.341$ \\
Used replacement hormonal therapy & 1.8258 & $1.637-10.590$ \\
Often exposed to stress & 0.9724 & $0.702-1.351$ \\
Reduced physical activity & 0.8919 & $0.746-1.065$ \\
Smoking & 0.9033 & $0.555-1.469$ \\
Length of smoking time (years) & 1.5314 & $0.756-3.098$ \\
Number of cigarettes per day & 0.6416 & $0.323-1.272$ \\
Exposure to smoking at home & 1.1260 & $0.788-1.608$ \\
Exposure to smoking at workplace & 1.2203 & $0.889-1.675$ \\
Alcohol consumption & 1.7283 & $0.396-7.533$ \\
Exposure to PAHs & 1.5007 & $0.336-6.691$ \\
Exposure to mercury & 1.1407 & $0.070-18.568$ \\
Length of working experience (years) & 1.1883 & $0.795-1.775$ \\
\hline * 2 inear logistic analysis & & \\
& &
\end{tabular}

\section{Discussion}

The biggest risk factor for the breast cancer, besides sex, is age. The older a person is the greater is the risk of getting this malignancy [20-24]. This conclusion is proven with our results. Women older than 45 have approximately 1.3 - fold higher risk of being affected with breast cancer, as results of aging. In our sample of 100 patients with recently discovered breast cancer, two out of 100 examinees $(2 \%)$ were in the 26-35 age group, 15 in the 36-45 ages, and the biggest number were above 45 years of age, 83 of them $(83 \%)$. Results are similar for other countries; e.g. in the UK, according to the data of the National Cancer Centre in 1996 [25]. Our results show higher frequency of breast cancer at a young age like in developed countries.

According to published studies women of high social status are at higher risk of getting breast cancer $[6,7,15,16]$. Our results are opposite to this statement and indicate that poverty and bad economic situation of the family, along with dissatisfaction with the mentioned situation, pose a significant risk factor for the genesis of breast cancer. However, the poorest, the unemployed, precarious living existence, poor financial status, with high BMI and low levels of physical activity are housewives. Perhaps, the main 
potentially reason is the existentially distress. We found negative trend for breast cancer in family history. If the grandmother had cancer increases the relative risk for nearly twice times more compared to the subjects without family predisposition $(\mathrm{OR}=2.2)$, but risk is 4 times higher if the breast cancer had a distant cousin $(\mathrm{OR}=4.4)$

Table 4: The association between potential predictors to breast cancer (independent variables) and breast cancer (dependent variable), and dichotomised occupation/ workplace as cofactor variable among the examinees with breast cancer $(n=100)$.

\begin{tabular}{lccc}
\hline $\begin{array}{l}\text { Predictors as independent } \\
\text { variables }\end{array}$ & $\begin{array}{c}\text { Standard } \\
\text { coefficients } \\
\boldsymbol{\beta}\end{array}$ & $\mathbf{P}$ & $\begin{array}{c}\text { 95\%Confidence } \\
\text { Interval }\end{array}$ \\
\hline Model 1 & & & \\
Age & 0.086 & 0.508 & $-0.191-0.382$ \\
Employability & 0.087 & 0.443 & $-0.067-0.153$ \\
Education & 0.094 & 0.506 & $-0.117-0.235$ \\
Home & 0.168 & 0.162 & $-0.053-0.311$ \\
Wealth status & 0.010 & 0.946 & $-0.143-0.153$ \\
Satisfaction with financial status & 0.074 & 0.595 & $-0.091-0.158$ \\
Stress & -0.088 & 0.437 & $-0.150-0.066$ \\
Routine physical activity & -0.070 & 0.543 & $-0.081-0.043$ \\
Smoking & 0.155 & 0.176 & $-0.017-0.093$ \\
Alcohol consumption & -0.031 & 0.789 & $-0.410-0.313$ \\
Work experience & -0.193 & 0.109 & $-0.402-0.041$ \\
Body mass index & 0.078 & 0.498 & $-0.018-0.038$ \\
Model 2 & & & \\
Age & & & \\
Employability & 0.153 & 0.224 & $-0.098-0.411$ \\
Education & 0.026 & 0.825 & $0.163-0.204$ \\
Home & 0.014 & 0.900 & $-0.79-0.090$ \\
Wealth status & -0.007 & 0.944 & $-0.161-0.149$ \\
Satisfaction with financial status & 0.135 & 0.313 & $-0.068-0.211$ \\
Stress & 0.023 & 0.860 & $-0.107-0.128$ \\
Routine physical activity & -0.006 & 0.955 & $-0.124-0.117$ \\
Smoking & -0.086 & 0.408 & $-0.090-0.037$ \\
Alcohol consumption & -0.043 & 0.664 & $-0.051-0.033$ \\
Work experience & 0.090 & 0.407 & $-0.107-0.262$ \\
Body mass index & -0.226 & 0.048 & $-0.202--0.001$ \\
\hline
\end{tabular}

ANOVA: dependent variable breast cancer; predictors: age, employability, education, home, wealth status, satisfaction with financial status, stress, routin physical activity, smoking, alcohol consumption, work experience. Model 1 , selecting part of variable occupation: 1 housewives (occupation variable was dichotomised). Model 2, selecting part of variable occupation: 2 other occupations (occupation variable was dichotomised) Pranjić N. Gledo I. The most common new cases of breast cancer among the housewives: the some carcinogenic determinants.

It is known that obesity and physical is associated with increased incidence of breast cancer $[1,11,24]$. A study conducted in Sweden and Finland has shown that obesity in older women (median age $56, \mathrm{BMl}>30$ ) increases the risk of breast cancer in younger women (median age 30 ) and shows inversion [3]. Our study patients were mostly in a group of overweight, $50 \%$ of them, obese $21 \%$ and $70 \%$ of them do not practiced physical training in the total sample [15]. Results related to physical activity as a protector of breast cancer varies in different studies, and for about $30-40 \%$ decrease risk for breast cancer $[1,2,11,20]$. On the other hand, women who do not have the habit of routine physical activity have a predictor of developing breast cancer [14, 17], as is the case in our patients. The previous experience in developed countries can be explained by factors of breast cancer associated with exposure to estrogens during reproductive time or change the concentration of this hormone in obese people, alcohol and persons with reduced physical activity [17]. Late menopause increases the risk of breast cancer. Women who have undergone the menopause have a lower risk of breast cancer than pre-menopausal women of the same age and childbearing pattern. Risk increases by almost $3 \%$ for each year later at menopause (natural or induced by surgery), so that a women who has the menopause at 55 rather than 45 , has approximately $30 \%$ higher risk [25]. However, we found that menopause among patients with breast carcinoma come much earlier related to control subjects. ( $\leq 40$ years $11 \%$; from 40 50 years $40 \% ; p=0.012$ ).

Every workplace has and/ or does not have its own specific carcinogen [19]. A large number of authors were studied which chemical environmental compounds which could be associated with breast cancer. The increasing risk for breast cancer was occurred with increased length of exposure to environmental risk. Some occupations are also associated with increased risk of breast cancer [26]. The housewives usually were suffered from this serious disease. However, occupation is not significant relative carcinogenic risk of developing breast cancer $(\mathrm{OR}=0.900, \mathrm{Cl}, 0.7814-1.037413$; Table 3).

This study is accompanied by certain difficulties and limitations. The basic limitation is the relatively small number of subjects. It was very difficult to assess occupational risk because only 25 examiners with carcinoma who are employed. Another important limitation of this study is the deficiencies in the registration some characteristics. Limitations in our study can be considered to absence of the adequate questionnaire for assessment to the intensity of stress/distress or possibly burnout syndrome because it seems that distress and burnout play very important role in genesis of breast cancer. Our housewives exposed to unsafe financial existence, poverty and unemployment as main life and breast cancer stressors perhaps.

We found numerous contradictory study results related to results from other authors, for example our patients with breast cancer have: increasing breast cancer risks among younger age groups (opposite to thesis that with increasing age increases breast cancer risk); low level of income (opposite to thesis that in develop country patients with breast cancer have usually high level of income); early menopause (opposite to thesis that later menopause is predictor for breast cancer); negative growth trend for breast cancer in the conditions of clearance to close relatives; our patients with breast cancer have mainly overweight or obesity which is not significantly breast cancer risk.

In summary, social determinants as low level of quality of life and bad life- style (specially reduced physical activity), environmental and workplace exposure risks for breast cancer could be associated with lack of well structured promotional and prevention oriented programs, aimed at adaptation of healthy lifestyles and adaptation of workplace, as a pre- requisite of better life quality among researched examiners. Despite expressing promotion actions to manage with women risks of breast cancer on the first place is 
education in local area about risks and healthy lifestyles. If family medicine team is to fulfil their gatekeeper role effectively and possibly become more involved in the delivery of knowledge your patients in the future. It is clear that they require further education in area of assessment of family cancer clinic for breast cancer. Patients are be educated on medical treatment side effect prevention (diagnostic CT or hormonal substitute treatment risks), elimination of workplace predictors of breast cancer (as rotating night shifts), or healthy food intake and protection with continued physical activity [25-27].

\section{References}

1. Berglund G. Anthropometry, physical activity and cancer of the breast and colon. In Riboli EL (ed) Nutrition and Lifestyle: Opportunities for Cancer Prevention. International Agency for Research on Cancer: IARC Scientific Publications. Lyons, 2002.

2. Vainio H, Bianchini F. Weight Control and Physical Activity. World Health Organization, International Agency for Research on Cancer: IARC Handbooks of Cancer Prevention. Lyons, 2002.

3. Gledo I, Pranjić N, Prasko S. Quality of Life Factor as Breast Cancer Risks. Mat Soc Med. 2012; 24(3): 171-7.

4. Brody JG, Rudel RA. Environmental pollutants and breast cancer. Environmental Health Perspectives. 2003; 111:1007-19.

5. Anderson BO, Shyyan R, Eniu A, Smith RA, et al. Breast cancer in limited-resource countries: An overview of the breast health global initiative 2005 guidelines. Breast Journal. 2006; 12 (1): S3S15.

6. Pukkala E, Weiderpass E. Time trends in socio- economic differences in incidence rates of cancers of the breast and female genital organs (Finland, 1971-1995). Int J Epidemiol. 1999; 81(1): 56-61.

7. Hemminki $\mathrm{K}$, Zhang $\mathrm{H}$, Czene $\mathrm{K}$. Socioeconomic factors in cancer in Sweden. Int J Cancer. 2003; 105(5): 692-700.

8. Danø $H$, Andersen $O$, Ewertz $M$, Petersen JH, Lynge $E$. Socioeconomic status and breast cancer in Denmark. Int $\mathrm{J}$ Epidemiol. 2003; 32: 218-24.

9. Hill DA, Preston- Martin S, Ross RK, Bernstein L. Medical radiation, family history of cancer, and benign breast disease in relation to breast cancer risk in young women, USA. Cancer Causes Control. 2002; 13(8): 711-8.

10. Chang SC, Ziegler RG, Dunn B, Stolzenberg- Solomon R, et al. Association of energy intake and energy balance with postmenopausal breast cancer in the prostate, lung, colorectal, and ovarian cancer screening trial. Cancer Epidemiol Biomarkers Prev. 2006; 15(2): 334-41.

11. Sprague BL, Trentham- Dietz A, Newcomb PA, at al. Lifetime recreational and occupational physical activity and risk of in situ and invasive breast cancer. Cancer Epidemiol Biomarkers Prev. 2007; 16(2): 236-243.

12. Tirona MT, Sehgal R, Ballester O. Prevention of breast cancer (Part I): epidemiology, risk factors, and risk assessment tools. Cancer Invest. 2010; 28:743-50.

13. Parody PW. Dairy Product Consumption and the Risk of Breast Cancer. J Am Coll Nutr. 2005; 24(6): 556S-68S

14. Key TJ, Appleby PN, Reeves GK, et al. Body mass index, serum sex hormones, and breast cancer risk in postmenopausal women, J Nat Cancer Inst. 2003; 95:1218-26.

15. Hemminki K, Li X. University and medical education and the risk of cancer in Sweden. Eur J Cancer Prev. 2004; 13(3): 199-205.
16. Fenton SE. Endocrine- disrupting compounds and mammary gland development: early exposure and later life consequences. Endocrinology. 2006; 147: S18-24.

17. Bergstrom A, Pisani P, Tenet V, Wolk A, Adami H. Overweight as an avoidable cause of cancer in Europe. Int J Cancer. 2001; 91: 421-30.

18. DeCensi A, Gennari A. Insulin Breast Cancer Connection: Confirmatory Data Set the Stage for Better Care. J Clinic Oncol. $2011 ; 29(1): 7-10$.

19. Autier P, Boniol M, LaVecchia C, Vatten L, et al. Disparities in breast cancer mortality trends between 30 European countries: retrospective trend analysis of WHO mortality database. BMJ. 2010; 34: c3620.

20. Cantor KP, Stewart PA, Brinton LA, Dosemeci M. Occupational exposures and female breast cancer mortality in the U.S. J Occup Environ Med. 1995; 37(3), 336-348.

21. Shaham J, Gurvich R, Goral A, Czerniak A. The risk of breast cancer in relation to health habits and occupational exposure. AJIM. 2006; 49(12): 1021.

22. Byrne C. Mammographic density: a breast cancer risk factor or diagnostic indicator? Acad Radiol. 2002; 9 (3): 253-5.

23. Office for National Statistics. Cancer statistics registration of cancer diagnosed in 2008, England. MBI, no 39. National Statistics, London, 2010.

24. Hansen J. Elevated risk for male breast cancer after occupational exposure to gasoline and vehicular combustion products. Am J Ind Med. 2000; 37: 349-352.

25. Watson E, Austoker J, Lucassena A. A study of GP referrals to a family cancer clinic for breast/ovarian cancer. Oxford Journals of Medicine, Family Practice. 2000; 18(2):131-34.

26. Kruk J. Lifetime physical activity and the risk of breast cancer: a case-control study. Cancer Detect Prev. 2007; 31 (1): 18-28.

27. The world Health Report 2002. Reducing risks, Promoting Health Report. World Health Organization; 2002.U.S. Department of Health and Human Services, Breast Cancer Screening, accessed online at www.ahrq.gov/clinic/uspstf/uspsbrca.htm, on Nov. 20, 2009. 